\title{
HLA-B Alleles B*15:01 and B*15:02: Opposite Association with Hepatitis C Virus Infection in Chinese Voluntary Blood Donors
}

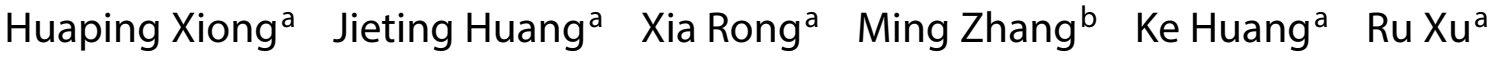 \\ Min Wang ${ }^{a}$ Chengyao Lic Qiao Liao ${ }^{a}$ Wenjie Xia ${ }^{a}$ Guangping Luo ${ }^{a}$ Xin Ye $^{a}$ \\ Ling Lu ${ }^{d}$ Yongshui Fu ${ }^{a}$ Tai Guo ${ }^{e}$ Kenrad Nelson ${ }^{f}$ \\ ${ }^{a}$ Guangzhou Blood Center, Guangzhou, Guangdong, China; ${ }^{b}$ Department of Epidemiology and Biostatistics, Faculty \\ of Infectious Diseases, University of Georgia, Athens, Ga., USA; ' $D$ Department of Transfusion Medicine, School of

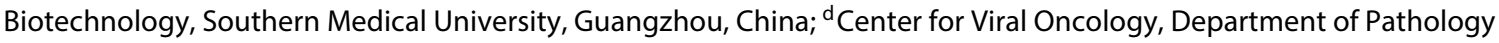

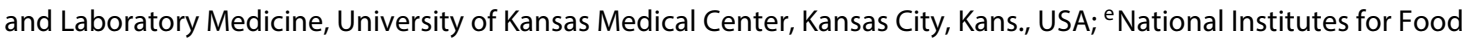 \\ and Drug Control, Beijing, China; ${ }^{f}$ Department of Epidemiology, Bloomberg School of Public Health, Johns Hopkins \\ University, Baltimore, Md., USA
}

\section{Key Words}

Hepatitis C virus - Chronic infection · Human leukocyte antigens · Alleles · Chinese population · Blood donor

\begin{abstract}
Background: Although human leukocyte antigens (HLA) have been shown in association with the outcomes of hepatitis $\mathrm{C}$ virus (HCV) infection among different ethnic groups, such studies remain absent in China, where the HCV prevalence is higher than the global average. Methods: In this study, 426 HCV-infected and 709 uninfected blood donors were analyzed, among whom the HLA alleles were sequenced using a high-resolution genotyping method. Results: At the 2-digit level, none of the alleles showed a statistical difference between the HCV-infected and uninfected groups. However, at the 4-digit level, the HLA-B alleles $B^{*} 15$ : 01 and $B^{*} 15: 02$ showed an opposite association with HCV infection, i.e. $B^{*} 15: 01$ was significantly higher in the HCV-infected group (odds ratio, $O R=1.561, p=0.010$ ), while $B^{*} 15$ :
\end{abstract}

H. Xiong and J. Huang contributed equally to the work.
() 2015 S. Karger AG, Basel

0300-5526/15/0582-0080\$39.50/0
02 was significantly higher in the uninfected group (OR = $0.778, p=0.016$ ). We also identified a higher frequency of $B^{*} 13: 02$ in the HCV-infected group (OR $\left.=1.515, p=0.009\right)$ and a higher frequency of $B^{*} 07: 05$ in the uninfected group $(O R=0.299, p=0.001)$. Conclusions: The frequencies of four HLA alleles, $B^{*} 07: 05, B^{*} 13: 02, B^{*} 15: 01$, and $B^{*} 15: 02$, were found to be significantly different between the HCV-infected and uninfected blood donors in China, revealing an inverse relation of $B^{*} 15: 01$ and $B^{*} 15: 02$ with $\mathrm{HCV}$ infection. This finding suggests that the ethnic genetic variations of HLA may greatly affect the host immune responses against HCV.

๑) 2015 S. Karger AG, Basel

\section{Introduction}

Hepatitis $\mathrm{C}$ virus (HCV) is a blood-borne pathogen that causes a major threat to global public health [1]. Currently, an estimated 170-210 million people worldwide are infected with the virus [2]. The majority of the infec-

\section{KARGER 125}

E-Mail karger@karger.com www.karger.com/int
Dr. Yongshui Fu

Guangzhou Blood Center

$31 \mathrm{Lu}$ Yuan Road

Guangzhou, Guangdong 510095 (China)

E-Mail fuyongshui1969@yahoo.com

Dr. Ling Lu

University of Kansas Medical Center

3901 Rainbow Boulevard

Kansas City, KS 66160 (USA)

E-Mail llu@kumc.edu 
tions are persistent and could finally result in hepatic fibrosis, liver cirrhosis, hepatocellular carcinoma, and other end-stage liver diseases [3]. To date, interferon- $\alpha$ plus ribavirin has been used as a recommended regimen; however, it is effective only in about half of the patients treated, and there remains a lack of reliable vaccines [4].

The host immunity can greatly influence the outcomes of HCV infection [5]. The robust and sustained immunological responses mediated by the activation of $\mathrm{CD} 4+$ and $\mathrm{CD} 8+$ cytotoxic $\mathrm{T}$ lymphocytes are the most important factors in determining viral clearance or persistence [6-8]. Evidence has shown that strong and broad $\mathrm{T}$-cell responses are correlated with viral clearance, while chronic HCV infection is associated with attenuated and narrowly focused CD4+ and CD8+ T-cell responses [9]. Both $\mathrm{T}$ cells recognize the viral antigens presented on the surface of the infected hepatocytes through binding the T-cell receptors to human leukocyte antigen (HLA) molecules that present the peptide fragments of the viral antigens. The HLA molecules are encoded by genes located on chromosome 6 , which is among the most polymorphic regions in human genomes. The diversity of HLA molecules is critical in predicting the susceptibility and outcomes of natural HCV infection in humans $[10,11]$.

Previous studies have revealed associations between the HLA patterns and host immune responses among individuals infected with human immunodeficiency virus type 1 (HIV-1) and hepatitis B virus (HBV) [12-15]. Studies have also shown the importance of HLA molecules to the natural outcomes of HCV infection. Although it has been reported in a few sufficiently sampled and well-designed studies that some alleles have strong associations with $\mathrm{HCV}$ infection [10,16-18], many other studies were limited due to a small study population, an inappropriate population stratification, lack of correction for multiple comparisons, or a low-resolution typing technique [5, 19]. Moreover, racial differences in the studies of association between the HLA patterns and the outcomes of HCV infection have also been identified [18-21]. Nevertheless, there have been few studies focusing on the Chinese population, which is the largest HCVinfected population in the world $[22,23]$.

In this study, we conducted a high-resolution typing of the HLA class I (A and B) and II (DRB1) alleles among a cohort of Chinese voluntary blood donors that included $426 \mathrm{HCV}$-infected (HCV Ab+/RNA+) and 709 uninfected individuals (HCV Ab-/RNA-). The identified allelic and genotypic frequencies revealed an opposite association of HLA-B alleles B*15:01 and B*15:02 with HCV infection.

HLA and the Susceptibility to HCV Infection in Chinese Blood Donors

\section{Materials and Methods}

\section{Subjects}

Blood samples were collected from voluntary blood donors at Guangzhou Blood Center, China, during the period of July 2009 to November 2011. A total of $426 \mathrm{HCV}$-infected and 709 uninfected blood donors were recruited. Before blood donation, all individuals were requested to complete a blood donation health consent form for their participation in the study. Physicians ensured that individuals were personally interviewed to assure their complete understanding of the informed consent. All of the participants provided their verbal informed consent by telephone. This study strictly followed the ethical guidelines of the 1975 Declaration of Helsinki and was approved by the Medical Ethics Committee of Guangzhou Blood Center.

\section{Pathogen Detection}

$\mathrm{HCV}, \mathrm{HBV}, \mathrm{HIV}$, and Treponema pallidum tests were performed for blood screening. Anti-HCV was assayed using two independent enzyme-linked immunosorbent kits (Kehua Biotech Co. Ltd., Shanghai, China and Abbott Laboratories, Chicago, Ill., USA; Abbott HCV EIA 2.0) [24]. HCV RNA was detected using nucleic acid testing (Procleix Ultrio Assay; Gen-Probe, San Diego, Calif., USA) according to the provider's guidance. HBV, HIV and T. pallidum were detected following the manufacturers' protocols [25]. All the HCV-infected donors were tested positive for both anti-HCV and HCV-RNA (HCV Ab+l RNA+) and negative for HIV antibodies, HBsAg (HBV surface antigen), T. pallidum antibodies, HBV and HIV nucleic acids, while the controls were found to be negative for all of these testing items.

\section{HLA-A, HLA-B and DRB1 Typing}

The HLA-A, HLA-B and DRB1 alleles were assigned using the HLA sequencing-based typing by following the manufacturer's protocols (AlleleSEQR HLA-A, AlleleSEQR HLA-B, AlleleSEQR HLA-DRB1; Atria Genetics, San Francisco, Calif., USA). Briefly, the target genes were amplified in a mixture containing AmpliTaq Gold DNA polymerase. The amplicons were purified using ExoSAP-IT (Atria Genetics) and sequenced in both directions (ABI 3730 DNA Sequencer; Applied Biosystems, Foster City, Calif., USA). The HLA alleles were assigned at a 4-digit level using the ASSIGN 3.5 software (Conexio Genomics, Perth, W.A., Australia). Synonymous mutations were not recorded, while those samples with ambiguous results were applied to additional haplotype sequencing [26].

\section{HCV Genotyping}

HCV genotypes were determined as previously described [25]. Some of the partial NS5B sequences of HCV have been previously reported [27]. In brief, the partial NS5B sequences of HCV were amplified using the Primer STAR kit (Takara, Dalian, China). The expected amplicons were sequenced in both directions on an ABI Prism 3100 genetic analyzer (PE Applied Biosystems, Foster City, Calif., USA). The obtained sequences were aligned using the CLUSTAL_X program. Phylogenetic trees were estimated based on the maximum-likelihood method under the $\mathrm{HKY}+\mathrm{I}+\mathrm{\Gamma}_{6}$ substitution model using the MEGA5 software. Bootstrap resampling was performed in 1,000 replicates. 
Table 1. General information about the studied blood donors

\begin{tabular}{lccc}
\hline Demographic data & $\begin{array}{l}\text { HCV-infected } \\
\text { donors }\end{array}$ & $\begin{array}{l}\text { Uninfected } \\
\text { donors }\end{array}$ & p value \\
\hline Total, $\mathrm{n}$ & 426 & 709 & \\
Age, years & $33.8 \pm 8.9$ & $31.0 \pm 8.9$ & 0.146 \\
Gender & $353(82.9)$ & $510(71.9)$ & $2.95 \mathrm{E}-05$ \\
$\quad$ Male & $73(17.1)$ & $199(28.1)$ & \\
$\quad$ Female & $418(98.1)$ & $700(98.7)$ & 0.414 \\
Ethnicity & $8(1.9)$ & $9(1.3)$ & \\
$\quad \begin{array}{l}\text { Chinese Han } \\
\quad \text { Others }\end{array}$ & & & \\
\hline
\end{tabular}

Values are $\mathrm{n}(\%)$ or means $\pm \mathrm{SD}$, as appropriate. Gender: significantly different between the two groups based on $\chi^{2}$ test $(\mathrm{p}<$ 0.05).

\section{Statistical Analysis}

The allelic and genotypic distribution at the HLA-A, HLA-B and DRB1 loci and their association with chronic HCV infection among the Chinese voluntary blood donors were analyzed using the $\chi^{2}$ test with SPSS 16.0 software. The strength of the associations was inferred by odds ratio (OR) with $95 \%$ confidence interval ( $95 \%$ $\mathrm{CI})$. For multiple comparisons, the false discovery rate method (described by Benjamini and Hochberg [28]) was used to calculate $q$ values to control the false discovery rate. Statistically significant associations were indicated when $\mathrm{q}$ values were less than 0.1 .

\section{Results}

\section{Characteristics of the Studied Donors}

General information on the studied donors is summarized in table 1 . They were all Chinese and predominantly of Han ethnicity. Of the $426 \mathrm{HCV}$-infected donors, $82.9 \%(353 / 426)$ were male and $17.1 \%(73 / 426)$ were female, while these percentages were $71.9 \%(510 / 709)$ and $28.1 \%$ (199/709), respectively, among the 709 controls. The male/female ratio was significantly higher in the former than in the latter group ( $\mathrm{p}=2.95 \mathrm{E}-05)$, which verified previous findings that males are more susceptible to $\mathrm{HCV}$ infection than females $[24,25]$. No significant difference was identified in age between the HCV-infected and uninfected group $(\mathrm{p}=0.146)$.

\section{HLA Alleles and Chronic HCV Infection}

To reveal possible associations between the HLA polymorphism and HCV infection, alleles at the HLA-A, HLA-B and DRB1 loci were sequenced. Of the $426 \mathrm{HCV}$ infected donors, reliable typing results were obtained for 413,415 and 416 at the HLA-A, HLA-B and DRB1 loci, respectively. Of the 709 control donors, reliable typing results were obtained for 658,650 and 683 . In total, 31 HLA-A, 64 HLA-B and 54 HLA-DRB1 alleles were identified. Table 2 lists the alleles that had frequencies $>1 \%$ among the studied subjects. At the HLA-A locus, 14 alleles showed frequencies $>1 \%$, accounting for $97.9 \%$ of the total HLA-A alleles identified. At the HLA-B locus, 18 alleles showed frequencies $>1 \%$, accounting for $86.7 \%$ of the total HLA-B alleles sequenced. Similarly, at the DRB1 locus, 18 alleles showed frequencies $>1 \%$, accounting for 93.5\% of the total HLA-DRB1 alleles detected.

Next, we analyzed the allele frequencies at the 2-digit level. The allele frequencies at three loci, HLA-A, HLA-B and DRB1, were not statistically different between the two study groups after adjusting for multiple variables (online suppl. table 1; for all online suppl. material, see www. karger.com/doi/10.1159/000369209). However, when analyzed at the 4-digit level, four alleles at the HLA-B locus were found to be significantly different between the two groups (table 2). $\mathrm{B}^{*} 13: 02(\mathrm{OR}=1.515, \mathrm{p}=0.009, \mathrm{q}<0.1)$ and $\mathrm{B}^{*} 15: 01(\mathrm{OR}=1.561, \mathrm{p}=0.010, \mathrm{q}<0.1)$ were significantly more frequent in the $\mathrm{HCV}$-infected group than in the control group. Reversely, $\mathrm{B}^{*} 07: 05(\mathrm{OR}=0.299, \mathrm{p}=$ $0.001, \mathrm{q}<0.05)$ and $\mathrm{B}^{*} 15: 02(\mathrm{OR}=0.778, \mathrm{p}=0.016, \mathrm{q}<$ 0.1 ) were significantly more frequent in the control group than in the HCV-infected group (table 2; fig. 1).

Analysis at the HLA-A and DRB1 loci also identified the alleles with marginally significant differences between the HCV-infected and uninfected groups. $A^{*} 30: 01$ and $A^{*} 33: 03(\mathrm{OR}=1.385, \mathrm{p}=0.033$ and $\mathrm{OR}=1.588, \mathrm{p}=0.027$, respectively) appeared to be more frequent in the HCVinfected group, while $A^{*} 29: 01(\mathrm{OR}=0.414, \mathrm{p}=0.010)$, $\mathrm{DRB}^{*} 10: 01(\mathrm{OR}=0.504, \mathrm{p}=0.008)$ and $\mathrm{DRB} 1 * 16: 02$ $(\mathrm{OR}=0.725, \mathrm{p}=0.012)$ appeared to be more frequent among the control group (table 2). However, they all failed to reach a significant level after a false discovery rate adjustment $(\mathrm{q}>0.1)$.

Finally, multivariate logistic regression analysis was used to estimate the independent risk factors for these alleles in association with HCV infection, adjusting for other possible modifiers or confounders such as age, gender, etc. Stepwise logistic regression analysis indicated that the following five variables were independently associated with HCV infection: (1) gender $(\mathrm{OR}=0.532, \mathrm{p}<0.001$, 95\% CI: $0.428-0.660)$, (2) HLA-B*07:05 allele (OR = 0.204, $\mathrm{p}=0.003,95 \%$ CI: 0.071-0.583), (3) HLA-B*15:02 allele (OR $=0.690, \mathrm{p}=0.023,95 \% \mathrm{CI}: 0.502-0.949)$, (4) HLA-B1 $* 13: 02$ allele $(\mathrm{OR}=2.217, \mathrm{p}=0.012,95 \% \mathrm{CI}$ : 1.193-4.120) and (5) HLA-B*15:01 allele $(\mathrm{OR}=2.319$, $\mathrm{p}=0.017,95 \%$ CI: 1.165-4.620; table 3). 
Table 2. Frequencies of HLA alleles between the two cohorts of blood donors

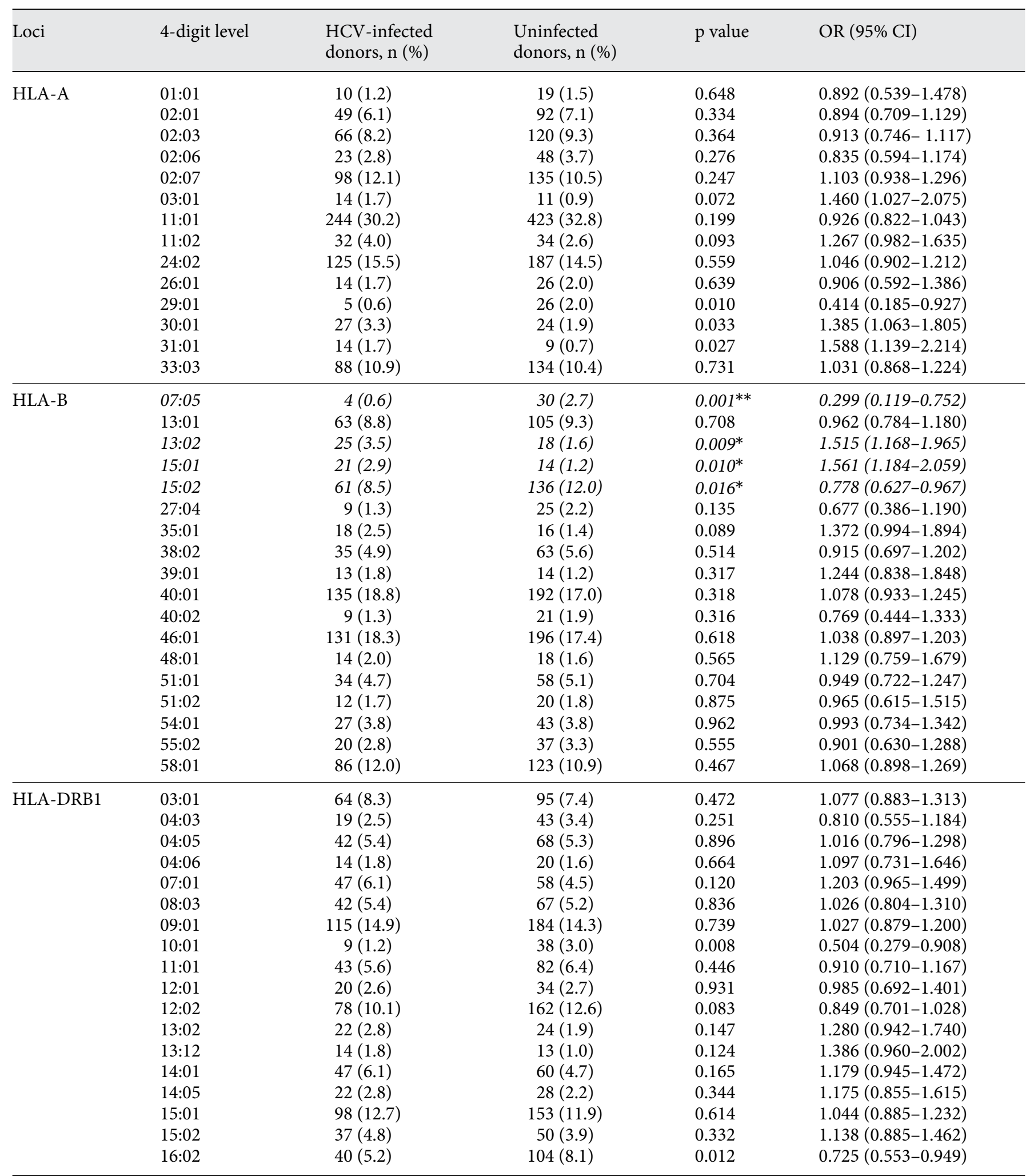

Alleles with frequencies higher than $1.0 \%$ are shown at the 4-digit level and analyzed. HLA-B: Alleles with statistical significance $(\mathrm{q}<$ $0.1)$ are indicated in italics. ${ }^{*} \mathrm{q}<0.1 ;{ }^{* *} \mathrm{q}<0.05$.

HLA and the Susceptibility to HCV Infection in Chinese Blood Donors 
Table 3. Multiple logistic regression analysis of variables associated with $\mathrm{HCV}$ infection

\begin{tabular}{llr}
\hline Variable & OR $(95 \%$ CI $)$ & p value \\
\hline Gender (F/M) & $0.532(0.428-0.660)$ & $<0.001$ \\
HLA-B*07:05 & $0.204(0.071-0.583)$ & 0.030 \\
HLA-B*13:02 & $2.217(1.193-4.120)$ & 0.012 \\
HLA-B*15:01 & $2.319(1.165-4.620)$ & 0.017 \\
HLA-B*15:02 & $0.690(0.502-0.949)$ & 0.023 \\
\hline
\end{tabular}

$\mathrm{p}$ values are $<0.05$

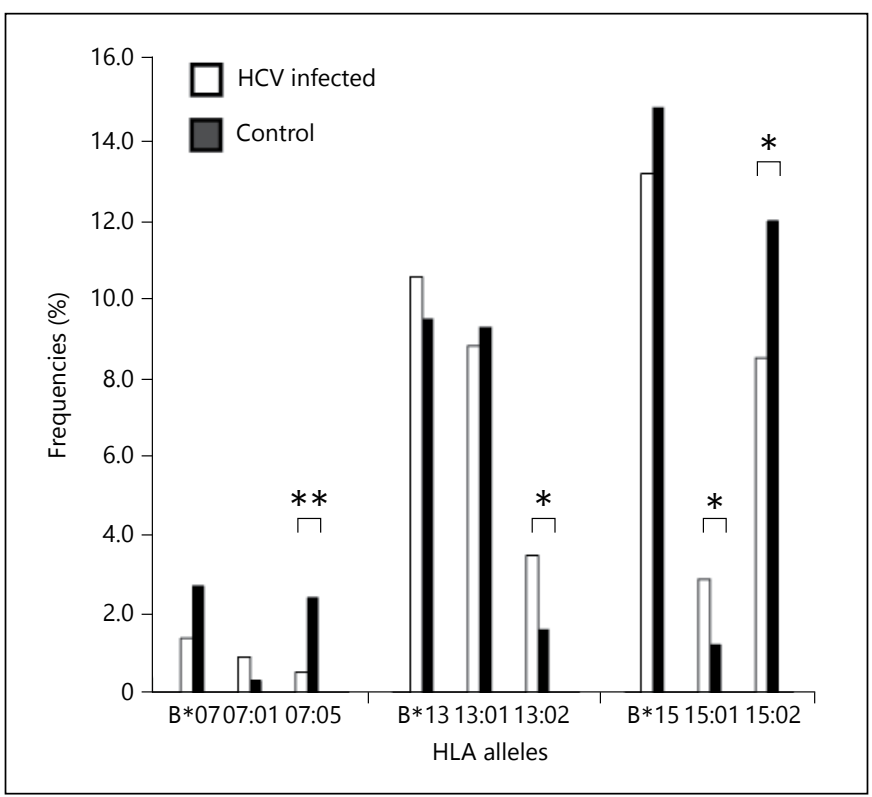

Fig. 1. Comparison of HLA alleles at the 2- and 4-digit levels in association with chronic HCV infection. The HLA-B alleles $\mathrm{B}^{*} 07$, $\mathrm{B}^{*} 13$ and $\mathrm{B}^{*} 15$ assigned at the 2-digit level were compared with their subordinates assigned at the 4-digit alleles. ${ }^{*} \mathrm{q}<0.1$; ${ }^{* *} \mathrm{q}<$ 0.05 .

\section{HLA Genotypes and Chronic HCV Infection}

A potential association between the HLA genotypes and HCV infection was also assessed. Different HLA-A genotypes showed varied frequencies between the two study groups $\left(\chi^{2}=41.565, \mathrm{p}=0.007\right.$; table 4$)$, while this was not the case for the HLA-B and DRB1 alleles $\left(\chi^{2}=\right.$ $27.537, \mathrm{p}=0.154$ and $\chi^{2}=31.086, \mathrm{p}=0.411$, respectively; online suppl. tables 2 and 3 ). Both $\mathrm{A}^{*} 02: 07 / \mathrm{A}^{*} 02: 07$ and $A^{*} 11: 01 / A^{*} 11: 02$ were significantly more frequent in the $\mathrm{HCV}$-infected group than in the control group $(\mathrm{OR}=$ $1.831, \mathrm{p}=0.021$ and $\mathrm{OR}=1.824, \mathrm{p}=0.011$, respectively). $\mathrm{A}^{*} 02: 07 / \mathrm{A}^{*} 11: 01$ was significantly more frequent in the control group than in the $\mathrm{HCV}$-infected group $(\mathrm{OR}=$ $0.612, \mathrm{p}=0.011$; table 4 ). However, after adjusting for multiple variables, this significance did not remain.

\section{HLA Alleles and HCV Genotypes}

To explore possible association between the HLA polymorphism and HCV genotypes, the alleles at the A, $B$ and DRB1 loci were further correlated with the 166 and 136 isolates of $\mathrm{HCV}$, which were determined from the $\mathrm{HCV}$-infected donors and classified into subtypes $1 \mathrm{~b}$ and $6 a$, respectively (online suppl. fig. 1). However, no significant differences were identified in this analysis (online suppl. table 4).

\section{Discussion}

In this study, we examined the association between the HLA alleles and HCV infection among a cohort of voluntary blood donors. To our knowledge, this represents the first study of such in China. Among the studied donors, all of those infected with HCV were asymptomatic and treatment naive and were therefore ideal for displaying the natural outcomes of $\mathrm{HCV}$ infection, representing the general population in the country where the HCV prevalence is above the global average.

Our results revealed that, at different levels, four HLA alleles, $B^{*} 07: 05, B^{*} 13: 02, B^{*} 15: 01$, and $B^{*} 15: 02$, were associated with $\mathrm{HCV}$ infection. Although such a relationship was not reported before, previous studies have shown the four alleles in association with other viral infections. Among Chinese patients, $B^{*} 07$ might protect hosts from HBV infection, $B^{*} 15$ was identified in association with HBV-C2 clearance [12], while $B^{*} 13$ was detected more often in the HIV-1-infected individuals with unusually low viral loads [15]. These findings, together with those from the present study, may indicate the varied antigenbinding properties of the polymorphic HLA alleles and their different roles played in the host antiviral immune responses.

The association between HCV infection and the four alleles, $\mathrm{B}^{*} 07: 05, \mathrm{~B}^{*} 13: 02, \mathrm{~B}^{*} 15: 01$, and $\mathrm{B}^{*} 15: 02$, may be simply attributed to the differences in certain ethnic factors. Previously, most of the studies in this regard were performed on Caucasians, Hispanics and Africans [10, 16-18], showing different results. For example, conflicting associations with $\mathrm{HCV}$ infection have been observed for the $A^{*} 02$ and DRB1* 12 alleles when both Caucasians and non-Caucasians were compared [19]. Thio et al. [18] identified that between white and black people the spe- 
Table 4. Frequencies of HLA-A genotype in the HCV-infected and control donors

\begin{tabular}{lccll}
\hline HLA-A genotype & $\begin{array}{c}\text { HCV-infected } \\
\text { donors, n }(\%)\end{array}$ & $\begin{array}{c}\text { Uninfected } \\
\text { donors, } \mathrm{n}(\%)\end{array}$ & p value & OR (95\% CI) \\
\hline $\mathrm{A}^{*} 02: 01 / \mathrm{A}^{*} 02: 03$ & $3(1.0)$ & $9(1.9)$ & 0.339 & $0.649(0.243-1.736)$ \\
$\mathrm{A}^{*} 02: 01 / \mathrm{A}^{*} 02: 07$ & $8(1.5)$ & $4(0.8)$ & 0.083 & $1.760(1.168-2.652)$ \\
$\mathrm{A}^{*} 02: 01 / \mathrm{A}^{*} 11: 01$ & $11(3.6)$ & $24(4.9)$ & 0.391 & $0.813(0.494-1.338)$ \\
$\mathrm{A}^{*} 02: 01 / \mathrm{A}^{*} 24: 02$ & $6(2.0)$ & $11(2.3)$ & 0.795 & $0.919(0.480-1.761)$ \\
$\mathrm{A}^{*} 02: 01 / \mathrm{A}^{*} 33: 03$ & $6(2.0)$ & $8(1.6)$ & 0.725 & $1.121(0.608-2.065)$ \\
$\mathrm{A}^{*} 02: 03 / \mathrm{A}^{*} 02: 07$ & $12(4.0)$ & $10(2.1)$ & 0.112 & $1.441(0.973-2.132)$ \\
$\mathrm{A}^{*} 02: 03 / \mathrm{A}^{*} 11: 01$ & $20(6.6)$ & $45(9.3)$ & 0.191 & $0.789(0.542-1.149)$ \\
$\mathrm{A}^{*} 02: 03 / \mathrm{A}^{*} 24: 02$ & $11(3.6)$ & $11(2.3)$ & 0.253 & $1.316(0.858-2.018)$ \\
$\mathrm{A}^{*} 02: 03 / \mathrm{A}^{*} 33: 03$ & $3(1.0)$ & $12(2.5)$ & 0.141 & $0.517(0.187-1.428)$ \\
$\mathrm{A}^{*} 02: 06 / \mathrm{A}^{*} 11: 01$ & $8(2.6)$ & $18(3.7)$ & 0.42 & $0.797(0.445-1.429)$ \\
$\mathrm{A}^{*} 02: 07 / \mathrm{A}^{*} 02: 07$ & $9(3.0)$ & $4(0.8)$ & $0.021^{*}$ & $1.831(1.260-2.660)$ \\
$\mathrm{A}^{*} 02: 07 / \mathrm{A}^{*} 11: 01$ & $17(5.6)$ & $53(10.9)$ & $0.011^{*}$ & $0.612(0.401-0.934)$ \\
$\mathrm{A}^{*} 02: 07 / \mathrm{A}^{*} 24: 02$ & $15(5.0)$ & $27(5.6)$ & 0.721 & $0.928(0.613-1.407)$ \\
$\mathrm{A}^{*} 02: 07 / \mathrm{A}^{*} 33: 03$ & $14(4.6)$ & $13(2.7)$ & 0.141 & $1.370(0.942-1.993)$ \\
$\mathrm{A}^{*} 11: 01 / \mathrm{A}^{*} 11: 01$ & $44(14.6)$ & $62(12.8)$ & 0.469 & $1.097(0.858-1.403)$ \\
$\mathrm{A}^{*} 11: 01 / \mathrm{A}^{*} 11: 02$ & $11(3.6)$ & $5(1.0)$ & $0.011^{*}$ & $1.824(1.295-2.569)$ \\
$\mathrm{A}^{*} 11: 01 / \mathrm{A}^{*} 24: 02$ & $32(10.6)$ & $68(14.0)$ & 0.164 & $0.815(0.604-1.101)$ \\
$\mathrm{A}^{*} 11: 01 / \mathrm{A}^{*} 26: 01$ & $4(1.3)$ & $11(2.3)$ & 0.348 & $0.692(0.297-1.609)$ \\
$\mathrm{A}^{*} 11: 01 / \mathrm{A}^{*} 30: 01$ & $9(3.0)$ & $7(1.4)$ & 0.136 & $1.482(0.953-2.305)$ \\
$\mathrm{A}^{*} 11: 01 / \mathrm{A}^{*} 33: 03$ & $27(8.9)$ & $48(9.9)$ & 0.863 & $0.933(0.681-1.280)$ \\
$\mathrm{A}^{*} 24: 02 / \mathrm{A}^{*} 24: 02$ & $11(3.6)$ & $12(2.5)$ & 0.341 & $1.257(0.813-1.945)$ \\
$\mathrm{A}^{*} 24: 02 / \mathrm{A}^{*} 33: 03$ & $16(5.3)$ & $16(3.3)$ & 0.165 & $1.322(0.924-1.891)$ \\
$\mathrm{A}^{*} 33: 03 / \mathrm{A}^{*} 33: 03$ & $5(1.7)$ & $8(1.6)$ & 0.992 & $1.004(0.502-2.008)$ \\
\hline
\end{tabular}

Genotypes with frequencies of $<1 \%$ are not shown. ${ }^{*} \mathrm{p}<0.05$.

cific HLA class II alleles, including $\mathrm{DRB} 1 * 01$, are differently associated with HCV infection outcomes. With reference to the two studies described above, the present study showed distinct patterns of the HLA polymorphism in association with the HCV infection among a subset of the Chinese blood donors.

To assess the association between the HLA polymorphism and HCV infection, we applied a high-resolution genotyping method, which can provide more robust information than using a low-resolution approach $[5,16]$. Although no statistical differences were found in the frequency of alleles at the 2-digit level between the HCVinfected and uninfected groups, at the 4-digit level four HLA-B alleles showed significantly different frequencies between these two groups. $B^{*} 15: 01$ and $B^{*} 15: 02$ showed opposite associations, with the former appearing as a risk allele and the latter possibly a favoring allele (fig. 1). A similar situation was also observed between the $\mathrm{B}^{*} 07: 01$ and $\mathrm{B}^{*} 07: 05$ alleles, although the former failed to reach a statistical threshold, probably due to its very low frequency of $<1 \%$. In a previous study on HIV- 1 infection, oppos- ing effects have been also observed for $\mathrm{B}^{*} 58: 01$ and $\mathrm{B}^{*} 58$ : 02 that may control the level of viremia [29]. To our knowledge, the opposing effects identified in this study on HCV infection could represent the first such report to date. We hypothesize that the differences in the amino acids encoded by these polymorphic alleles $\left(\mathrm{B}^{*} 15\right.$ : 01/B*15:02 and $\left.\mathrm{B}^{*} 07: 01 / \mathrm{B}^{*} 07: 05\right)$ may have affected the HLA properties in binding antigens, structurally or functionally or both, and this could have contributed to the different outcomes of HCV infection. However, because the underlying molecular mechanism is not clear, further studies are therefore required. Such studies will not only lead to a better understanding of the host-HCV interactions but will also help in developing new strategies for ultimate HCV eradication.

In this study, we also examined the association between the HLA alleles and HCV genotypes. HCV is known to be genetically diverse, with 6 genotypes and more than 80 subtypes that are now classified [30]. Such a high degree of genetic heterogeneity may have caused variable immune responses of the hosts that are deter- 
mined by different patterns of the HLA alleles. A previous study has identified different distributions of the HLA class I alleles between infections with HCV subtypes 1a and $1 \mathrm{~b}$ [31]. The HLA-restricted variations between HCV infections with subtypes $1 \mathrm{a}$ and $3 \mathrm{a}$ have been also indicated [32]. Recently, we have demonstrated that the infection with HCV subtype 6a is increasingly prevalent among patients and blood donors in Guangdong province, China, and this has made $6 \mathrm{a}$ and $1 \mathrm{~b}$ the two major HCV subtypes detected in that geographic region [25, 27]. However, there remains a knowledge gap about the association between the HLA polymorphism and HCV genotypes in the general population in the country. In this study, we tried to address this issue but failed to obtain significant findings, probably for two reasons. First, some of the HLA alleles were undetected in this study, possibly due to their very low frequencies among the asymptomatic blood donors we recruited, while these alleles may be more common among the symptomatic patients infected with more virulent strains of HCV. Second, possible associations between the HLA alleles and HCV amino acid variations were not inspected, while their interactions are deemed to play important roles in predicting the outcomes of HCV infection [16, 33, 34]. Future studies are needed to examine these possibilities.

It should be noted that if more information can be obtained from those donors who have spontaneously cleared the HCV infection, namely those who were HCVAb+/ RNA- when analyzed, in comparison with those who have an existing HCV infection, more robust conclusions could be made that would be useful for predicting the outcomes of the natural HCV infection. Based on the results from the present study, it may be hypothesized that the described patterns of HLA alleles somehow interact with certain ethnic factors in determining the host susceptibility to persistent HCV infection, and this is more prominent among a subset of the Chinese population. Unfortunately, due to the lack of such donors who subsequently cleared the HCV infection during the period of prospective observation, we were unable to test this hypothesis in detail. Nevertheless, for this purpose we are now recruiting more blood donors with natural HCV infection. It is our expectation that such a widely organized prospective study will greatly facilitate the exploration of the roles played by the described patterns of HLA alleles in association with spontaneous HCV clearance in the Chinese population.

In conclusion, we identified the possible association of four HLA alleles, $B^{*} 07: 05, B^{*} 13: 02, B^{*} 15: 01$, and $B^{*} 15: 02$, with HCV infection among a cohort of voluntary blood donors who may ideally represent the general population in China, among whom $B^{*} 15: 01$ and $B^{*} 15: 02$ appeared to play opposing roles. This finding not only supports the premise that the HLA polymorphic patterns are ethnically specific but also partially fills in a knowledge gap of the association between the HLA alleles and HCV infection in the Chinese population.

\section{Acknowledgments}

This work was supported by the Key Medical Disciplines and Specialties Program of Guangzhou, a grant from the National Natural Science Foundation of China (No. 81273145), a grant from the 12th Five-year National Science \& Technology Major Project (2012ZX10004702), and a grant from NIAID/NIH (5 R01 AI080734-03A). The funding agencies had no role in the study design, data collection and analysis, decision to publish, or preparation of the manuscript.

\section{References}

1 Hepatitis C - global prevalence (update). Wkly Epidemiol Rec 1999;74:425-427.

2 El-Shabrawi MH, Kamal NM: Burden of pediatric hepatitis C. World J Gastroenterol 2013;19:7880-7888.

3 Chevaliez S, Pawlotsky JM: Hepatitis C virus: virology, diagnosis and management of antiviral therapy. World J Gastroenterol 2007;13: 2461-2466.

-4 Tanaka Y, Nishida N, Sugiyama M, Kurosaki M, Matsuura K, Sakamoto N, Nakagawa M, Korenaga M, Hino K, Hige S, Ito Y, Mita E, Tanaka E, Mochida S, Murawaki Y, Honda M, Sakai A, Hiasa Y, Nishiguchi S, Koike A, Sakaida I, Imamura M, Ito K, Yano K, Masaki N, Sugauchi F, Izumi N, Tokunaga K, Mizo- kami M: Genome-wide association of IL28B with response to pegylated interferon- $\alpha$ and ribavirin therapy for chronic hepatitis $\mathrm{C}$. Nat Genet 2009;41:1105-1109.

5 Yee LJ: Host genetic determinants in hepatitis C virus infection. Genes Immun 2004;5:237245.

-6 Lechner F, Gruener NH, Urbani S, Uggeri J, Santantonio T, Kammer AR, Cerny A, Phillips R, Ferrari C, Pape GR, Klenerman P: $\mathrm{CD} 8+\mathrm{T}$ lymphocyte responses are induced during acute hepatitis $\mathrm{C}$ virus infection but are not sustained. Eur J Immunol 2000;30: 2479-2487.

7 Lechner F, Wong DK, Dunbar PR, Chapman R, Chung RT, Dohrenwend P, Robbins G,
Phillips R, Klenerman P, Walker BD: Analysis of successful immune responses in persons infected with hepatitis C virus. J Exp Med 2000;191:1499-1512.

8 Thimme R, Oldach D, Chang KM, Steiger C, Ray SC, Chisari FV: Determinants of viral clearance and persistence during acute hepatitis C virus infection. J Exp Med 2001;194: 1395-1406.

-9 Klenerman P, Hill A: T cells and viral persistence: lessons from diverse infections. Nat Immunol 2005;6:873-879.

$\rightarrow 10$ Hraber P, Kuiken C, Yusim K: Evidence for human leukocyte antigen heterozygote advantage against hepatitis $C$ virus infection. Hepatology 2007;46:1713-1721. 
11 Piertney SB, Oliver MK: The evolutionary ecology of the major histocompatibility complex. Heredity (Edinb) 2006;96:7-21.

-12 Li X, Liu W, Wang H, Jin X, Fang S, Shi Y, Liu Z, Zhang S, Yang S: The influence of HLA alleles and HBV subgenotyes on the outcomes of HBV infections in Northeast China. Virus Res 2012;163:328-333.

13 Roe DL, Lewis RE, Cruse JM: Association of HLA-DQ and -DR alleles with protection from or infection with HIV-1. Exp Mol Pathol 2000;68:21-28.

14 Singh R, Kaul R, Kaul A, Khan K: A comparative review of HLA associations with hepatitis $B$ and $C$ viral infections across global populations. World J Gastroenterol 2007;13:17701787.

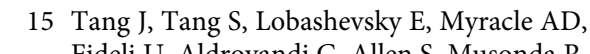
Fideli U, Aldrovandi G, Allen S, Musonda R, Kaslow RA: Favorable and unfavorable HLA class I alleles and haplotypes in Zambians predominantly infected with clade $\mathrm{C}$ human immunodeficiency virus type 1. J Virol 2002;76: 8276-8284.

16 Kuniholm MH, Kovacs A, Gao X, Xue X, Marti D, Thio CL, Peters MG, Terrault NA, Greenblatt RM, Goedert JJ, Cohen MH, Minkoff H, Gange SJ, Anastos K, Fazzari M, Harris TG, Young MA, Strickler HD, Carrington $\mathrm{M}$ : Specific human leukocyte antigen class I and II alleles associated with hepatitis C virus viremia. Hepatology 2010;51:15141522.

17 Thio CL, Gao X, Goedert JJ, Vlahov D, Nelson KE, Hilgartner MW, O’Brien SJ, Karacki P, Astemborski J, Carrington M, Thomas DL: HLA-Cw*04 and hepatitis C virus persistence. J Virol 2002;76:4792-4797.

18 Thio CL, Thomas DL, Goedert JJ, Vlahov D, Nelson KE, Hilgartner MW, O’Brien SJ, Karacki P, Marti D, Astemborski J, Carrington M: Racial differences in HLA class II associations with hepatitis $C$ virus outcomes. J Infect Dis 2001;184:16-21.

19 Wang JH, Zheng X, Ke X, Dorak MT, Shen J, Boodram B, O'Gorman M, Beaman K, Cotler SJ, Hershow R, Rong L: Ethnic and geographical differences in HLA associations with the outcome of hepatitis $C$ virus infection. Virol J 2009;6:46.
20 Hoggart CJ, Parra EJ, Shriver MD, Bonilla C, Kittles RA, Clayton DG, McKeigue PM: Control of confounding of genetic associations in stratified populations. Am J Hum Genet 2003; 72:1492-1504.

21 Sarmiento OL, Ford CL, Newbern EC, Miller WC, Poole C, Kaufman JS: The importance of assessing effect modification when asserting racial differences in associations between human leukocyte antigen class II alleles and hepatitis C virus outcomes. J Infect Dis 2002;185: 266-268.

22 Shen Y, Cao D, Li Y, Kulski JK, Shi L, Jiang H, Ma Q, Yu J, Zhou J, Yao Y, Shi L: Distribution of HLA-A, -B, and -C Alleles and HLA/KIR combinations in Han population in China. J Immunol Res 2014;2014:565296.

23 Yu RB, Hong X, Ding WL, Tan YF, Zhang YX, Sun NX, Wu GL, Zhan SW, Ge DF: The association between the genetic polymorphism of HLA-DQA1, DQB1, and DRB1 and serum alanine aminotransferase levels in chronic hepatitis $\mathrm{C}$ in the Chinese population. J Gastroenterol Hepatol 2008;23:1394-402.

24 Fu Y, Xia W, Wang Y, Tian L, Pybus OG, Lu L, Nelson K: The seroprevalence of hepatitis $\mathrm{C}$ virus (HCV) among 559,890 first-time volunteer blood donors in China reflects regional heterogeneity in $\mathrm{HCV}$ prevalence and changes in blood donor recruitment models. Transfusion 2010;50:1505-1511.

25 Fu Y, Wang Y, Xia W, Pybus OG, Qin W, Lu L, Nelson K: New trends of HCV infection in China revealed by genetic analysis of viral sequences determined from first-time volunteer blood donors. J Viral Hepat 2010;18:4252.

26 Deng Z, Wang D, Xu Y, Gao S, Zhou H, Yu Q, Yang B: HLA-C polymorphisms and PCR dropout in exons 2 and 3 of the $\mathrm{Cw}^{*} 0706$ allele in sequence-based typing for unrelated Chinese marrow donors. Hum Immunol 2010; 71:577-581.
27 Rong X, Lu L, Wang J, Xiong H, Huang J, Chen J, Huang K, Xu R, Wang M, Zhang X, Guo T, Liu Y, Gao G, Fu Y, Nelson KE: Correlation of viral loads with HCV genotypes: higher levels of virus were revealed among blood donors infected with 6a strains. PLoS One 2012;7:e52467.

28 Green GH, Diggle PJ: On the operational characteristics of the Benjamini and Hochberg false discovery rate procedure. Stat Appl Genet Mol Biol 2007;6:article 27.

29 Kiepiela P, Leslie AJ, Honeyborne I, Ramduth D, Thobakgale C, Chetty S, Rathnavalu P, Moore C, Pfafferott KJ, Hilton L, Zimbwa P, Moore S, Allen T, Brander C, Addo MM, Altfeld M, James I, Mallal S, Bunce M, Barber LD, Szinger J, Day C, Klenerman P, Mullins J, Korber B, Coovadia HM, Walker BD, Goulder PJ: Dominant influence of HLA-B in mediating the potential co-evolution of HIV and HLA. Nature 2004;432:769-775.

30 Simmonds P: Genetic diversity and evolution of hepatitis $C$ virus - 15 years on. J Gen Virol 2004;85:3173-3188.

-31 Lange CM, Roomp K, Dragan A, Nattermann J, Michalk M, Spengler U, Weich V, Lengauer T, Zeuzem S, Berg T, Sarrazin C: HLA class I allele associations with HCV genetic variants in patients with chronic HCV genotypes $1 \mathrm{a}$ or $1 \mathrm{~b}$ infection. J Hepatol 2010;53:10221028.

32 Rauch A, James I, Pfafferott K, Nolan D, Klenerman P, Cheng W, Mollison L, McCaughan G, Shackel N, Jeffrey GP, Baker R, Freitas E, Humphreys I, Furrer H, Gunthard HF, Hirschel B, Mallal S, John M, Lucas M, Barnes E, Gaudieri S: Divergent adaptation of hepatitis $C$ virus genotypes 1 and 3 to human leukocyte antigen-restricted immune pressure. Hepatology 2009;50:1017-1029.

33 McKiernan SM, Hagan R, Curry M, McDonald GS, Kelly A, Nolan N, Walsh A, Hegarty J, Lawlor E, Kelleher D: Distinct MHC class I and II alleles are associated with hepatitis $\mathrm{C}$ viral clearance, originating from a single source. Hepatology 2004;40:108-114.

34 Rauch A, Gaudieri S, Thio C, Bochud PY: Host genetic determinants of spontaneous hepatitis C clearance. Pharmacogenomics 2009;10:1819-1837.
HLA and the Susceptibility to HCV Infection in Chinese Blood Donors 